\title{
Preference of service providers for the veterinary service-a case study of Sangli District of Maharastra state, I ndia
}

\author{
Pallavi P.Mirajkar, Sanjay Kumar* and Y.P.Singh \\ Division of Livestock Economics, Statistics \& Information Technology \\ Indian Veterinary Research Institute, I zatnagar-243122, UP, I ndia. \\ * Corresponding author email : sanjay@ivri.up.nic.in
}

\begin{abstract}
Availability of veterinary services is very important for development of livestock sector in India. In many locations apart from state veterinary services other veterinary services are also available and the veterinary service users have the choice available with them regarding the service providers. The preference of service providers depend upon the location, distance, livestock holding and capacity to pay and quality of services. A study was conducted among the livestock owners of Sangli district in Maharastra to assess the preference of the livestock owners towards a particular veterinary service provider. Majority of large farmers preferred state veterinary services and cooperative veterinary services where it had strong presence. Cooperative veterinary service can be a good alternative to the state veterinary services and the private veterinary service providers are still not preferred in the rural area.
\end{abstract}

Key words: Veterinary service,Livestock, Maharashtra, Disease, Rural India.

\section{I ntroduction}

Animal health service delivery system is an abstraction which is used to describe the way in which knowledge, skill and other resources related to animal health are organized within an economy for the delivery of services to animals and their keepers. They further stated that the purpose of animal health services delivery system is to optimize the use of resources and improve the welfare of the animals and humans by reducing diseases (Mlangwa and Kisauzi, 1994). Animal health service in most production systems covers three main areas i.e. animal health, production human health protection and extension services. It is fact that animal health services are directly related to the production. As livestock services, like other agricultural services in developing countries, have undergone changes after liberalization, livestock producers are faced with a range of service delivery organizations, public and private. It is timely to document what livestock producers look for in service delivery, and how they evaluate the organizations that deliver services.

Veterinary Services apply the skills, knowledge and resources of the veterinary profession to the protection and improvement of human and animal health. These Services make an indispensable contribution to the physical, mental and social welfare of humans (Van Leewen, 2002).Prabhaharan (2000) pointed out that the present day livestock husbandry system, characterized by more intensive production, capital intensive technologies and more commercialized operations all requiring a higher level of veterinary services, outline the need for provision of quality services even at low cost in India. He further suggested that the mandate of the government with regard to livestock should be modified in such a way that the current veterinary services and artificial breeding be moved to private hands and the government departments devote their energy on disease prevention and control.

There is a growing demand among producers and consumers for veterinary services to protect the health of animals and the safety of products of animal origin for both domestic and international markets. Livestock service around the world are usually delivered through a system composed of government institution and to greater or lesser extent, organization and individual belonging to the private sector (Kleeman, 1999).

For the most of South Asia including India government is direct provider of the services and the services are either delivered free of charge or with subsidies (Ahuja and Redmond, 2004). India has one of the largest animal health infrastructure and technical expertise in the world.

Ever since the beginning of planning era, efforts have been made to reduce economic losses due to 
Preference of service providers for the veterinary service

Table - 1: Respondent's preference for different veterinary service providers.

\begin{tabular}{|c|c|c|c|c|c|c|c|c|c|}
\hline \multirow[t]{2}{*}{ Preferences } & \multicolumn{3}{|c|}{ BlockA } & \multicolumn{3}{|c|}{ Block B } & \multicolumn{3}{|c|}{ Block C } \\
\hline & Small & Medium & Large & Small & Medium & Large & Small & Medium & Large \\
\hline Government & $5(31.25)$ & $2(11.78)$ & $2(28.57)$ & $9(45)$ & $8(53.33)$ & $1(20)$ & $6(20.68)$ & 0 & $1(25)$ \\
\hline Private & 7 (43.75) & $7(41.17)$ & $1(14.28)$ & $5(25)$ & $1(6.66)$ & $2(40)$ & $17(58.62)$ & $4(57.14)$ & $2(50)$ \\
\hline Cooperative & $1(6.25)$ & $1(5.88)$ & $3(42.85)$ & $3(15)$ & $1(6.66)$ & $1(20)$ & $6(20.68)$ & $3(42.85)$ & 0 \\
\hline Govt. + Private & $3(18.75)$ & $5(29.41)$ & $1(14.29)$ & $1(5)$ & $2(13.33)$ & 0 & 0 & 0 & $1(25)$ \\
\hline Private + Coope. & 0 & $1(5.88)$ & 0 & 0 & $1(6.66)$ & 0 & 0 & 0 & 0 \\
\hline Govt. + Coope. & 0 & $1(5.88)$ & 0 & $2(10)$ & $2(13.33)$ & $1(20)$ & 0 & 0 & 0 \\
\hline
\end{tabular}

mortality and morbidity through strengthening the infrastructure for animal health. The provision of animal health service in India is in the domain of public sector and many health service activities like quarantine, service during diseases prevalence, quality control, research and extension are mainly responsibility of government (Singh et al., 1998). In India, recognizing the importance of livestock to rural poor and their inability to avail the fully paid livestock services, the Government in centre and the state have been extending these services at a huge subsidy with their vast veterinary institutional network built up in the last 5 decades through many livestock sector promotion schemes to augment livestock production as well as productivity. In addition there are cooperatives, NGO's and private entrepreneurs endeavoring these livestock services to lesser extent. In this background it was felt important to provide evidences by analyzing the existing situation of the livestock health services delivery system.

\section{Material and methods}

Maharashtra state was chosen purposively for the present research work as the first author belongs to this state and well versed with the local language and dialect of the area. Selection of the ultimate respondents was based on simple stratified random sampling method of sampling. Three Talukas Palus,(A) Miraj (B)and Islampur taluka (C) out of 9 talukas in the Sangli district were selected randomly. It was assumed that selected talukas represented the population of district. From each selected block, four villages each out of total villages in each block were selected randomly. Ankalkhop, Bhilwadi, Palus and Santgoan villages from Palus taluka; Kavatepiran Kasbedigraj Nandre and Samdoli villages from Miraj taluka and Bavachi, Dhavali, Gotkhindi and Nagaon villages from Islampur taluka were selected. The list of all farmers of the selected villages having at least one animal was prepared and from each village 10 farmers
*Figure in the parentheses indicates the percentage were selected randomly following the simple random sampling method.

Thus a total of 120 respondent households made up the sample for the present study. The data from selected respondents was collected through the specially designed and pre tested interview schedule.

\section{Results}

The respondents were asked to indicate their major preference to different available service providers viz. veterinary officer at village veterinary hospital, veterinary officer of dairy cooperative, private practitioner, N.G.O's and traditional healer from all the three blocks viz. Palus, Miraj, Islampur. The table 1 shows that in block A majority farmers preferred private practitioners as these practitioners reach to farmers door step at any time by any mean when farmers called them. The private practitioners reach to remote areas to give veterinary service, but majority of large farmers $(42 \%)$ preferred veterinary services provided by the dairy cooperative as they had large livestock population and it was mandatory in the part of the dairy cooperative to give best veterinary service to their member farmers. In block B major preference of respondents was for State department of animal husbandry (government veterinary officer). The respondents from this block thought that the veterinary charges charged by government service provider for availing services were much less than that of cooperative and private veterinary officer's fees.

The highest percentage of respondents from block $\mathrm{C}$ favors private practitioner. Some villages from block $\mathrm{C}$ had no government veterinary officer appointed in veterinary dispensaries. In study area no respondent was approached for local healer to treat the animal here it shows that there was availability of veterinary service providers in study area. The literacy level among respondents was high in study area which causes this result that farmers treat their animals from veterinary practitioner who treats their animals 
with proper knowledge.

\section{Discussion}

Majority farmers in block A and C preferred private practitioners as these practitioners reached to farmers door step at any time by any means when farmers called them. But majority of large farmers (42\%) preferred veterinary services provided by the dairy cooperative as they had large livestock population and it was mandatory in the part of the dairy cooperative to give best veterinary service to their member farmers. In block B major preference of respondents was for State department of animal husbandry (government veterinary officer). In study area no respondent approached for local healer to treat the animal here it shows that there was availability of veterinary service providers in study area. The literacy level among respondents was high in study area which causes this result that farmers treat their animals from veterinary practitioner who treats their animals with proper knowledge.

\section{Acknowledgement}

The authors acknowledge the Director and Vice
Chancellor, Indian Veterinary Research Institute and Deemed University for providing fellowship. We also acknowledge the respondent farmers of the study from Sangli Ditrict, Maharastra for their time and information provided by them for the study.

\section{References}

1. A.P.Patil, et.al. (2009): Constraints Faced by the Dairy Farmers in Nagpur District while Adopting Animal Managenment Practices Vet. World, 2(3):111-112

2. Ahuja, V. and Redmond, E., (2004 ). Livestock service and the poor. Tropical Animal Health and Prod. 36, 247-268.

2. Kleeman G, (1999). Resources of the livestock services delivery and its management to the Asian economic crisis. Procedings of the workshop on the implication of the livestock industry held at Bangkok. Organised by FAO.

3. Mlangwa, J.E.D. and Kisauzi, D.N. (1994). System approach to animal health services delivery in sub-Saharan Africa: Concept development. Rev.Sci.Tech. 13, (3): 665-672.

4. Prabaharan, R. (2000). Livestock -Research investment crucial. The Hindu Survey of Indian Agriculture Chennai, The Hindu. Newspaper.

5. Singh, R. et.al. (1998). Review of animal health service in India. Ind. J. of Animal Sci. 68(5):420-424.

6. VanLeewen J.A., et.al. (2002). La sanità dell'ecosistema: un campo essenziale della medicina veterinaria. Progr.vet. (www.ilprogresso veterinari ofnovi.it/rivista/02n02/spe03. htm). 